\title{
Eleven years of management of children with intestinal failure and not candidates for intestinal transplantation
}

This article was published in the following Dove Press journal:

Transplant Research and Risk Management

31 August 2010

Number of times this article has been viewed

\section{Spagnuolo \\ MP Cicalese \\ E Bruzzese \\ MA Caiazzo \\ S Di Caro \\ $\checkmark$ Squeglia \\ A Guarino}

Department of Paediatrics, University Federico II, Naples, Italy
Correspondence: Maria Immacolata Spagnuolo

Department of Paediatrics, University

Federico II, Naples, Via S. Pansini,

580 I3I Naples, Italy

$\mathrm{Tel}+390817464337$

Fax +390817464337

Email mispagnu@unina.it
Background: Children with intestinal failure need parenteral nutrition to survive, and the only alternative is intestinal transplantation which still entails high mortality. The aim of this study was to compare the outcomes in candidates and noncandidates for intestinal transplantation, and to compare the outcomes with and without transplant surgery.

Patients and methods: The clinical records of children admitted to hospital from 1997 to 2008 because of intestinal failure were reviewed for etiology of intestinal failure, age at start of parenteral nutrition, duration of parenteral nutrition, indications for intestinal transplantation, and outcome.

Results: Thirty-four children were enrolled. Median age at start of parenteral nutrition was 13.1 (median 20.7) months. There was no difference in survival rate between candidates and noncandidates for intestinal transplantation. Survival was significantly higher in candidates who did not undergo intestinal transplantation than in children who underwent intestinal transplantation $(P<0.001)$.

Conclusion: Candidates for intestinal transplantation who did not undergo transplant surgery had a better outcome than children who underwent transplant surgery.

Keywords: intestinal transplantation, intestinal failure, parenteral nutrition, children

\section{Introduction}

Irreversible intestinal failure as a result of short bowel syndrome or other primary intestinal condition is associated with permanent loss of intestinal function. ${ }^{1-3}$ Management of children with intestinal failure is optimized by multidisciplinary coordination of parenteral and enteral nutrition support, medical management of associated complications, surgical lengthening procedures, and intestinal transplantation. Aggressive medical and nutritional intervention along with early referral, intestinal lengthening procedures, and intestinal transplantation in children with intestinal failure dependent on parenteral nutrition can result in achievement of enteral autonomy and improved survival. ${ }^{4}$

Although a life-saving option, parenteral nutrition is associated with a number of severe complications, including catheter-related sepsis, parenteral nutrition-related cholestasis, and metabolic abnormalities. ${ }^{3}$ According to the International Registry of Intestinal transplantation, the numbers of transplantations performed and intestinal transplantation centers have increased rapidly over recent years. ${ }^{5-7}$ However, intestinal transplantation still entails a high mortality and enormous costs, and the decision to refer a child for intestinal transplantation should be based on optimal prognostic evaluation of each individual case. Outcome evaluation shows a relatively high mortality for children transplanted in the last 10 years, in both the short and long term. ${ }^{7-10}$ 
At present, intestinal transplantation is indicated in cases of irreversible intestinal failure and any of the following conditions: progressive parenteral nutrition-related liver disease, defined as persistence of plasma bilirubin above $3 \mathrm{mg} / \mathrm{dL}$ for at least four months or irreversible liver disease with cirrhosis; recurrent catheter-related sepsis, defined as at least two episodes of sepsis per year secondary to central line infections or one episode of fungal sepsis or one major septic complication (ie, septic shock, multiorgan failure, metastatic abscess, etc); or loss of central venous access, and specifically two of the four available standard access sites for infants and three of the six sites for older children. ${ }^{5,11,12}$

Contraindications to intestinal transplantation include severe neurologic disability, life-threatening conditions not related to the primary gastrointestinal disease, congenital or acquired immune deficiency, malignancies, and autoimmune diseases.

The aim of this study was to compare the history and outcomes in children with intestinal failure and parenteral nutrition candidates for transplant surgery, who did not undergo intestinal transplantation, and in children not candidates for intestinal transplantation. In particular, we compared the outcomes of the group of patients who were candidates for transplant surgery who did not undergo intestinal transplantation with that reported in the literature for patients who underwent transplant surgery over an 11-year period.

\section{Patients and methods}

Children admitted to our unit from January 1997 to April 2008 because of intestinal failure were reviewed. We recruited two cohorts of patients, ie, children without indications for intestinal transplantation and children who were candidates for intestinal transplantation and who did not undergo transplant surgery. Intestinal failure was defined as a clinical condition resulting from a primary intestinal disease, for which parenteral nutrition provided at least $75 \%$ of the total caloric input for not less than four weeks, or $50 \%$ of calories for not less than thee months. ${ }^{3}$ For each child, data were recorded on primary etiology of intestinal failure, age at start and duration of parenteral nutrition, indication for intestinal transplantation, and outcome. We used the etiologic classification of intestinal failure reported by Goulet and Ruemmele, ${ }^{5}$ ie, short bowel syndrome, disorders of intestinal motility, structural enterocyte defects, food intolerance, and autoimmune enteropathy. After 11 years of management, clinical data for the study patients were analyzed to determine retrospectively the indications for transplant surgery. Indications for intestinal transplantation were independently evaluated by two investigators according to criteria from international position papers. ${ }^{5,11,12}$ A child was considered to have been a candidate for intestinal transplantation only when blind concordant indications were provided by two investigators in the absence of specific contraindications for the procedure. The age at which the indication for intestinal transplantation occurred was also recorded. We evaluated all parameters in candidates for intestinal transplantation and in children who were not candidates for intestinal transplantation. We also compared survival between intestinal transplantation candidates who did not undergo transplant surgery at our reference center and survival of patients reported in the literature who underwent intestinal transplantation. ${ }^{7}$

\section{Statistical analysis}

Age at which parenteral nutrition was started and its total duration were expressed as medians and ranges. Differences between candidates and noncandidates for intestinal transplantation were analyzed by the $\chi 2$ test for mortality and permanent weaning from parenteral nutrition. Age at starting parenteral nutrition and its duration were compared using the Student's t-test. Kaplan-Meier survival curves were constructed for intestinal transplantation candidates and noncandidates. Statistical differences between the curves were analyzed by log rank test. Statistical analysis was performed using SPSS version 11.5.

\section{Results}

Thirty-four children with intestinal failure were enrolled in the study. The primary etiologies of intestinal failure are reported in Table 1. Median age at starting parenteral nutrition was 13.1 months (range $0-155$ months). Median duration of parenteral nutrition was 20.7 (range 2-62) months and the median observation period was 48.2 (range 2-132) months. Nine children $(26 \%)$ were identified as candidates for intestinal transplantation and 25 (74\%) did not have a recorded indication for transplant surgery. Indication for intestinal transplantation occurred after a median 10.7 (range 2-20) months of parenteral nutrition.

Table I Etiologies in 34 children with intestinal failure enrolled from January 1997 to April 2008

\begin{tabular}{ll}
\hline Etiology & Number (\%) \\
\hline Short bowel syndrome & $24(70)$ \\
Chronic intestinal pseudoobstruction & $5(15)$ \\
Microvillus inclusion disease & $\mathrm{I}(3)$ \\
Primary bile acid malabsorption & $\mathrm{I}(3)$ \\
Unknown & $3(9)$ \\
\hline
\end{tabular}


There were no significant differences in age at start of parenteral nutrition, duration of parenteral nutrition, and duration of follow-up between candidates and noncandidates for intestinal transplantation (data not shown). In Table 2, the features of children with intestinal failure who had indications for intestinal transplantation are presented. The outcomes for the children were also compared. After a median follow-up of 28.4 (range 2-64) months, seven of the nine (78\%) intestinal transplantation candidates were still on parenteral nutrition, one was weaned from parenteral nutrition, and another had died (Table 3). The causes of death in the two groups of patients are presented in Table 4. Univariate analysis of specific outcomes between intestinal transplantation candidates and noncandidates revealed that noncandidates had higher rates of weaning of parenteral nutrition than candidates $(P<0.005$, Table 3, Figure 1). In our population, the survival rate for intestinal transplantation candidates was $87.5 \%$, which was very similar to survival of noncandidates $(82 \%$, not statistically significant). One-year patient and intestine graft survival was $89 \%$ and $79 \%$, respectively, for intestineonly recipients, as reported in the recent literature. ${ }^{7}$ By 10 years, patient and intestinal graft survival falls to $46 \%$ and $29 \%$ for intestine-only recipients. ${ }^{7}$ As shown in Figure 2, this was significantly higher in candidates who did not undergo transplant surgery than in children who underwent transplant surgery $(P<0.001)$.

\section{Discussion}

Major transplantation centers recognize common indications for intestinal transplantation in selected groups, ${ }^{5,10}$ but the incidence of morbidity and mortality following intestinal transplantation remains relatively high compared with other solid organ transplants. ${ }^{3}$ Progress in parenteral nutrition has resulted in a substantial reduction of major complications, such as micronutrient deficiencies, loss of vascular access, and central line infections, with excellent long-term results at experienced centers. ${ }^{1}$

Ursodeoxycholic acid appeared to be an effective treatment for total parenteral nutrition-related cholestasis in children, avoiding the need for combined transplantation in children with intestinal failure. ${ }^{13}$ The traditional prognostic value of small bowel length as a predictor of irreversibility of intestinal failure has been challenged. ${ }^{3}$ In this rapidly evolving field, the indications for intestinal transplantation or parenteral nutrition should be regarded as being purely indicative and need to be considered in relation to each individual patient.

In this single-center study, we evaluated the outcome of 34 children with intestinal failure. Nine children had indications for intestinal transplantation during a mean period of 10.7 months of parenteral nutrition. We found that noncandidates for intestinal transplantation were more likely to be weaned from parenteral nutrition, which suggests that their condition was less severe and reversible. However, there were no significant differences in mortality rates between the two groups. In our population of intestinal transplantation candidates, survival rate was $87.5 \%$ after a median observation period of 28.4 months. Management of intestinal failure should include therapies appropriate to each type and stage of intestinal failure based on a multidisciplinary approach, in centers involving pediatric surgery, pediatric gastroenterology, parenteral nutrition expertise, a home parenteral nutrition program, and liver-intestinal transplantation experience.

Timing for referral of patients to specialized centers remains a crucial issue. The main causes of intestinal failure have been briefly reviewed, emphasizing the medicosurgical strategy for prevention and provision of care, adapted to each

Table 2 Features of children with intestinal failure with indications for intestinal transplantation

\begin{tabular}{lllll}
\hline Etiology of IF & $\begin{array}{l}\text { Age at start } \\
\text { PN (months) }\end{array}$ & $\begin{array}{l}\text { Months on PN } \\
\text { before indication } \\
\text { to ITx }\end{array}$ & $\begin{array}{l}\text { Specific indication } \\
\text { to ITx }\end{array}$ & $\begin{array}{l}\text { Follow up after } \\
\text { indication } \\
\text { to ITx (months) }\end{array}$ \\
\hline CIP & 12 & 10 & Recurrent central line sepsis & 31 \\
MID & 1 & 8 & Recurrent central line sepsis & 29 \\
SBS & 1 & 1 Recurrent central line sepsis & 64 \\
SBS & 1 & 19 & Recurrent central-line sepsis & 58 \\
SBS & 2 & 7 & Liver cirrhosis & 18 \\
SBS & 1 & 20 & Loss of venous accesses & 17 \\
SBS & 1 & 2 & Multiorgan failure & 2 \\
SBS & 3 & 14 & Recurrent central line sepsis & 24 \\
SBS & 2 & 6 & Recurrent central line sepsis & 13 \\
\hline
\end{tabular}

Abbreviations: CIP, chronic intestinal pseudo-obstruction; MID, microvillus inclusion disease; SBS, short bowel syndrome. 
Table 3 Outcome of 34 children with intestinal failure (nine candidates versus 25 noncandidates for intestinal transplantation)

\begin{tabular}{lllll}
\hline Outcome & $\begin{array}{l}\text { Candidates } \\
\text { for ITx }\end{array}$ & $\begin{array}{l}\text { Noncandidates } \\
\text { for ITx }\end{array}$ & $\begin{array}{l}\text { All } \\
\text { patients }\end{array}$ & P \\
\hline Weaning & $1 / 9$ & $15 / 25$ & $16 / 34$ & $<0.005$ \\
Permanent & $7 / 9$ & $6 / 25$ & $13 / 34$ & $<0.05$ \\
PN & & & & \\
Deceased & $1 / 9$ & $4 / 25$ & $5 / 34$ & 1.0 \\
\hline
\end{tabular}

Abbreviations: PN, parenteral nutrition; Itx, intestinal transplantation.

type and stage of intestinal failure. ${ }^{4,14}$ Of course, no conclusion can be drawn from a comparison of these data with those of transplantation centers, but these results challenge the indications and optimal timing of referring children with intestinal failure for intestinal transplantation. An earlier referral may be requested to reduce poor outcomes related to transplantation in a child in desperate circumstances. ${ }^{6} \mathrm{On}$ the other hand, if applied without proper individual clinical judgment, intestinal transplantation may lead to early- and late-onset complications, with increased mortality compared with long-term parenteral nutrition. In some cases, intestinal transplantation could even prevent achievement of successful intestinal function. ${ }^{3}$

Like other highly sophisticated procedures, the outcome of intestinal transplantation depends on the experience of the transplantation center. ${ }^{8}$ This raises the question of availability and reliability of referral transplantation centers for children with intestinal failure. Moreover, with intestinal transplantation being a relatively new therapeutic option, there are complex ethical issues involved in the management of these children. ${ }^{5}$

In conclusion, the natural history of intestinal failure is better in noncandidates than in candidates for intestinal transplantation. However, the outcome for intestinal transplantation candidates who do not receive intestinal transplantation and remain on parenteral nutrition is very similar to that of children who undergo intestinal transplantation, according to data from the Intestinal Transplant Registry. ${ }^{7,15}$

Table 4 Causes of death in four patients (four candidates and one noncandidate for transplant surgery)

\begin{tabular}{llll}
\hline Cause of death & $\begin{array}{l}\text { Candidates } \\
\text { to ITx }\end{array}$ & $\begin{array}{l}\text { Noncandidates } \\
\text { to ITx }\end{array}$ & $\begin{array}{l}\text { All } \\
\text { patients }\end{array}$ \\
\hline $\begin{array}{l}\text { Severe sepsis } \\
\text { Microvillus }\end{array}$ & & $3 / 4$ & 3 \\
inclusion disease & I/4 & I \\
$\begin{array}{l}\text { Poor compliance } \\
\text { to TPN }\end{array}$ & I/I & & I \\
Total & I & 4 & 5 \\
\hline
\end{tabular}

Abbreviations: TPN, total parenteral nutrition; Itx, intestinal transplantation.

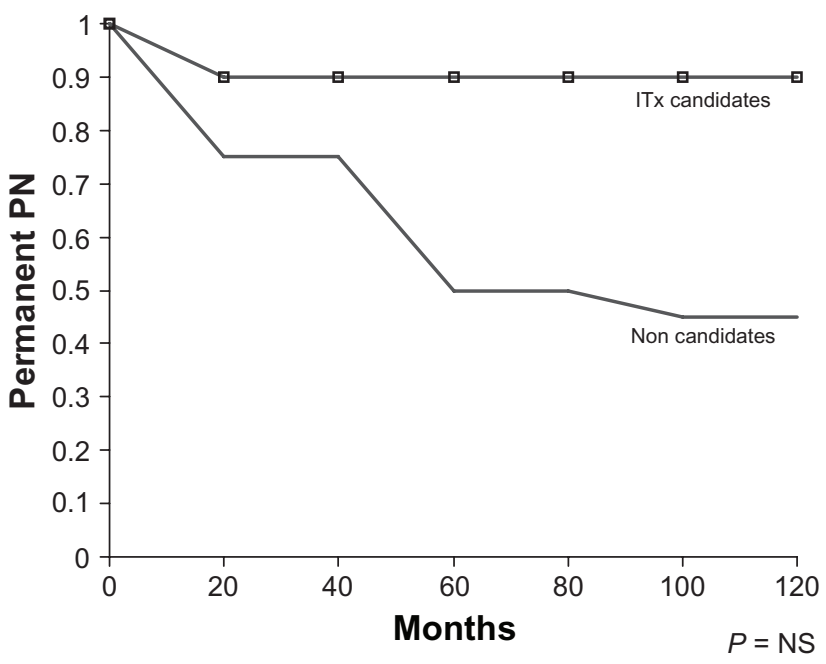

Figure I Time needed for weaning from parenteral nutrition in children who were candidates $(n=9)$ versus those who were not candidates for intestinal transplantation $(n=25)$.

The etiology of intestinal failure should be considered as the key point when selecting children for intestinal transplantation or other therapeutic options. ${ }^{6,7}$ For example, the observation that children with congenital microvillus atrophy almost invariably have a poor outcome underlies the proposal of early referral for intestinal transplantation. ${ }^{8-10}$ Anyway, at present, the indications for intestinal transplantation should be considered, taking into account the possibility of spontaneous reversibility of some causes of intestinal failure, such as tufting enteropathy, or some cases of very short bowel syndrome, and the fact that many children with so-called irreversible intestinal failure are in fact able to be weaned from parenteral nutrition. ${ }^{5}$ More studies are needed to identify the best available therapeutic strategy for children with intestinal failure and to improve the outcomes for children undergoing intestinal transplantation.

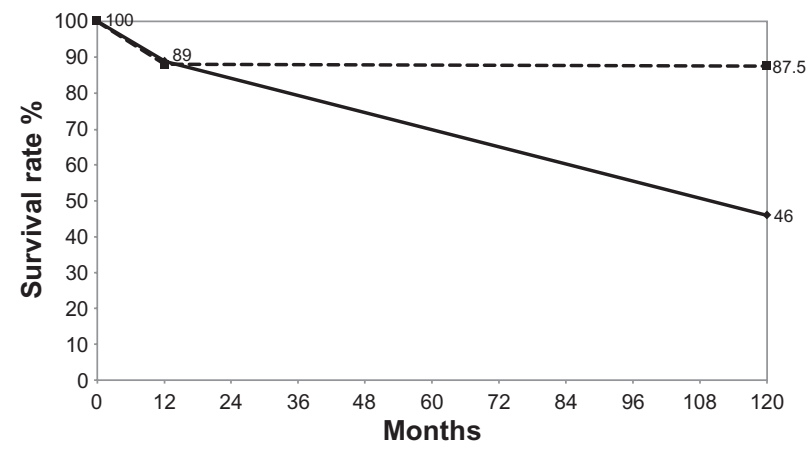

Figure 2 Indirect comparative evaluation of pediatric candidates who did not undergo intestinal transplantation with that reported for transplanted children. Continuous line shows the survival rate of transplanted children reported in literature. ${ }^{7}$ Dotted line shows survival rate of children candidates to intestinal transplantation who did not undergo transplant surgery in our center. 


\section{Acknowledgment}

This research was supported by a grant from the Ministry of University and Research; Progetti di Ricerca di Interesse Nazionale - PRIN 2007.

\section{Disclosure}

The authors report no conflicts of interest in this work.

\section{References}

1. Lacaille F, Jobert-Giraud A, Colomb V, et al. Preliminary experience with combined liver and small bowel transplantation in children. Transplant Proc. 1998;30:2526-2527.

2. Goulet O. Intestinal failure in children. Transplant Proc. 1998; 30:2523-2525.

3. Guarino A, De Marco G. Italian Network for Paediatric Intestinal Failure. Natural history of intestinal failure, investigated through a national network-based approach. J Pediatr Gastroenterol Nutr. 2003;37:36-41.

4. Nucci A, Burns RC, Armah T, et al. Interdisplinary management of pediatric intestinal failure: A 10-year review of rehabilitation and transplantation. J Gastrointest Surg. 2008;12:429-436.

5. Goulet $\mathrm{O}$, Ruemmele F. Causes and management of intestinal failure in children. Gastroenterology. 2006;130:S16-S28.

6. Glover JJ, Caniano DA, Balint J. Ethical challenges in the care of infants with intestinal failure and lifelong total parenteral nutrition. Semin Pediatr Surg. 2001;10:230-236.
7. Mazariegos GV, Steffick DE, Horslen S, et al. Intestine transplantation in the United States, 1999-2008. Am J Transplant. 2010;10(4 Pt 2): 1020-1034.

8. Beath SV. Closure and summary of Ninth International Small Bowel Transplantation Symposium. Transplant Proc. 2006;38:1657-1658.

9. O'Keefe SJ, Emerling M, Koritsky D, et al. Nutrition and quality of life following small intestinal transplantation. Am J Gastroenterol. 2007;102:1093-1100.

10. Millar AJ, Gupte GL. Small bowel transplantation in children. $\mathrm{Br} J$ Hosp Med (Lond). 2007;68:19-23.

11. Kaufman SS, Atkinson JB, Bianchi A, et al. Indications for paediatric intestinal transplantation: A position paper of the American Society of Transplantation. American Society of Transplantation. Pediatr Transplant. 2001;5:80-87.

12. Spagnuolo MI, Ruberto E, Guarino A. Isolated liver transplantation for treatment of liver failure secondary to intestinal failure. Ital J Pediatr. 2009;35:28

13. Spagnuolo MI, Iorio R, Vegnente A, et al. Ursodeoxycholic acid for treatment of cholestasis in children on long-term total parenteral nutrition: A pilot study. Gastroenterology. 1996;111:716-719.

14. Goulet O, Fusaro F, Lacaille F, et al. Permanent intestinal failure. Indian Pediatr. 2008;45:753-763.

15. Ruiz P, Kato T, Tzakis A. Current status of transplantation of the small intestine. Transplantation. 2007;83:1-6.
Transplant Research and Risk Management

\section{Publish your work in this journal}

Transplant Research and Risk Management is an international, peerreviewed open access journal focusing on all aspects of transplantation and risk management to achieve optimal outcomes in the recipient improving survival and quality of life. The journal welcomes submitted papers covering original research, basic science, clinical studies,

\section{Dovepress}

reviews \& evaluations, guidelines, expert opinion and commentary, case reports and extended reports. The manuscript management system is completely online and includes a very quick and fair peer-review system, which is all easy to use. Visit http://www.dovepress.com/ testimonials.php to read real quotes from published authors. 